Research Article

\title{
Through-Thickness Residual Stresses, Microstructure, and Mechanical Properties of Electron Beam-Welded CA6NM Martensitic Stainless Steel after Postweld Heat Treatment
}

\author{
Sheida Sarafan $\mathbb{D}^{1,2}$ Priti Wanjara $\mathbb{D}^{2},{ }^{2}$ Jean-Benoît Lévesque, ${ }^{1,3}$ Javad Gholipour, ${ }^{2}$ \\ Henri Champliaud, ${ }^{1}$ and Louis Mathieu ${ }^{4}$ \\ ${ }^{1}$ École de Technologie Supérieure, Montreal H3C $1 \mathrm{~K} 3$, Canada \\ ${ }^{2}$ National Research Council Canada Montreal, Montreal H3T 2B2, Canada \\ ${ }^{3}$ Institut de Recherche d'Hydro-Québec Varennes, Varennes J3X 1S1, Canada \\ ${ }^{4}$ GE Renewable Energy-Hydro North America Sorel-Tracy, Brossard J3R 5P9, Canada
}

Correspondence should be addressed to Sheida Sarafan; sheida.sarafan.1@ens.etsmtl.ca

Received 8 July 2019; Revised 2 December 2019; Accepted 3 December 2019; Published 12 February 2020

Academic Editor: Andres Sotelo

Copyright $\odot 2020$ National Research Council of Canada. This is an open access article distributed under the Creative Commons Attribution License, which permits unrestricted use, distribution, and reproduction in any medium, provided the original work is properly cited.

\begin{abstract}
In this study, the integrity of electron beam- (EB-) welded CA6NM-a grade of $13 \% \mathrm{Cr}-4 \% \mathrm{Ni}$ martensitic stainless steel-was assessed through the entire joint thickness of $90 \mathrm{~mm}$ after postweld heat treatment (PWHT). The joints were characterized by examining the microstructure, residual stresses, global mechanical properties (static tensile, Charpy impact, and bend), and local properties (yield strength and strain at fracture) in the metallurgically modified regions of the EB welds. The applied PWHT tempered the "fresh" martensite present in the microstructure after welding, which reduced sufficiently the hardness $(<280 \mathrm{HV})$ and residual stresses $(<100 \mathrm{MPa})$ to meet the requirements for hydroelectric turbine assemblies. Also, the properties of the EB joints after PWHT passed the minimum acceptance criteria specified in ASME sections VIII and IX. Specifically, measurement of the global tensile properties indicated that the tensile strengths of the EB welds in the transverse and longitudinal directions were on the same order as that of the base metal (BM). Evaluation of the local tensile properties using a digital image correlation (DIC) methodology showed higher local yield strengths in the fusion zone (FZ) and heat-affected zone (HAZ) of $727 \mathrm{MPa}$ and $740 \mathrm{MPa}$, respectively, relative to the $\mathrm{BM}$ value of $663 \mathrm{MPa}$. Also, the average impact energies for the $\mathrm{FZ}$ and $\mathrm{HAZ}$ were $63 \mathrm{~J}$ and $148 \mathrm{~J}$, respectively, and attributed to the different failure mechanisms in the HAZ (dimples) versus the FZ (quasi-cleavage consisting of facets and dimples). This study shows that the application of PWHT plays an important role in improving the weld quality and performance of EB-welded CA6NM and provides the essential data for validating the design and manufacturing process for nextgeneration hydroelectric turbine products.
\end{abstract}

\section{Introduction}

EBW is an established technology that has been widely adopted for high integrity fabrication of critical assemblies, especially in the aerospace sector [1]. In other industries, the ever-increasing demands for higher performance products have brought about increasingly stringent and extreme requirements for joining that, over the years, has been considered through the selection of EBW to achieve high quality, as well as flexible and cost-effective manufacturing
[2]. For instance, to improve the power generating efficiency and reliability of hydroelectric power systems, the most critical component, the turbine assembly-that consists of various heavy section subcomponents made of low carbon martensitic stainless steels (e.g., runner blades, crown, and band) welded together-must be designed and manufactured for high performance (strength and toughness), as well as low operational and maintenance requirements over its long-service life of more than five decades [3]. Presently, the turbine assembly is joined using a multitude of passes with 
GMAW or FCAW processes in the manual or semiautomated mode; hence, the product quality, manufacturing repeatability, and performance reliability are highly dependent on the operator skills. Even so, these conventional arc welding processes are inherently high in heat input, which renders considerable part distortion, pronounced residual stresses, and large metallurgically modified regions (FZ and HAZs) in the assembly [4]. By contrast, advanced high energy density processes, such as EBW, can offer considerable technological advantages for full penetration in thick gage sections by means of an autogenous single pass process. High penetration depth and low heat input characteristics of EBW [1] generate a narrow FZ with a restricted $\mathrm{HAZ}$, as well as minimized shrinkage and distortion [2] that, in turn, are promising for more uniform and/or reliable mechanical performance.

Therefore, EBW has been envisioned as a candidate process for the manufacture of next-generation hydroelectric turbine products to take advantage of its high power density capability that can generate narrow and deep welds to penetrate heavy sections in a single pass without the need for welding consumables [5]. Typically, hydroelectric turbine products are assembled from thick-walled stainless steel materials, such as CA6NM, a low-carbon 13\% Cr-4\% Ni martensitic grade that is manufactured in cast form, and has high strength, good toughness, and corrosion resistance [6]. However, transfer of the manufacturing design for turbine products from conventional arc welding to EBW necessitates a good understanding of the process impacts on the weldability and performance of the turbine material(s). To generate the essential performance data needed to validate turbine product design for manufacturing assembly with EBW, a multiyear collaboration was undertaken to evaluate the feasibility of the process to join heavy section turbine materials, such as CA6NM [7] and UNS S41500 [8]. The mechanical performance data generated for both materials indicated that the welds exhibited high strength and toughness $[9,10]$ without PWHT. However, the residual stresses after EBW ( $600 \mathrm{MPa})$ CA6NM [11] were $110 \%$ of the YS of the alloy and greater than that recommended to prevent the initiation of unstable/premature failure. Thus, understanding the role of PWHT on the characteristics and properties of CA6NM EB welds is crucial for comprehensive assessment of the process feasibility to guide industrial practice for manufacturing low-carbon $13 \%$ Cr- $4 \% \mathrm{Ni}$ martensitic stainless steels. With this objective, the present study on PWHT of heavy section ( $90 \mathrm{~mm}$ thick) EB welds in CA6NM was undertaken to characterize the microstructure, microhardness, global mechanical properties (static tensile, Charpy impact, and bend), local properties ( $\mathrm{YS}_{\mathrm{L}}$ and strain), and through-thickness residual stresses.

\section{Experimental Procedure}

In consideration of the design specifications for hydroelectric turbine manufacturing, the material selected for welding was $90 \mathrm{~mm}$ thick cast ASTM A743 grade CA6NM [12] in the normalized and double-tempered (Table 1) condition. The chemical composition (wt.\%) of the CA6NM alloy was $11.74 \% \mathrm{Cr}, 3.64 \% \mathrm{Ni}, 0.58 \% \mathrm{Mn}, 0.013 \% \mathrm{C}, 0.45 \%$ Mo, $0.50 \% \mathrm{Si}, 0.025 \% \mathrm{P}$, and $0.015 \% \mathrm{~S}$, as measured by optical emission spectroscopy, inert gas fusion (for $\mathrm{O}$ and $\mathrm{N}$ ), and high temperature combustion (for $\mathrm{C}$ and $\mathrm{S}$ ) methods.

Before welding, coupons-250 $\mathrm{mm}$ long, $80 \mathrm{~mm}$ wide, and $90 \mathrm{~mm}$ thick-were machined from normalized and tempered CA6NM. For each weld, two coupons with a square butt joint configuration and no intentional gap were tack welded, demagnetized, and fixed in a clamping fixture for butt welding (Figure 1(a)), as described in [10].

The recommended guideline for welding heavy sections (>12 mm thick) of $13 \% \mathrm{Cr}-4 \% \mathrm{Ni}$ martensitic stainless steel is to reduce the cooling rate during solidification by preheating from $100^{\circ} \mathrm{C}$ to $170^{\circ} \mathrm{C}[7,14,15]$. To preheat the CA6NM inside the EBW chamber, an EBZHT [16] was developed and validated by the authors previously $[7,10,15]$. In this study, multiple EBZHT passes were conducted to achieve the required temperature range. The preheated joints were then autogenously EB welded in the flat position (1G) using a $42 \mathrm{~kW}$ Sciaky W2000 EBW system $(60 \mathrm{kV} / 700 \mathrm{~mA})$ at a pressure lower than $6.7 \times 10^{-3} \mathrm{~Pa}$. The EB was defocused by $12 \%$ and positioned at $63 \mathrm{~mm}$ below the top surface of the coupon. The welding conditions enabled nearly full penetration in the $90 \mathrm{~mm}$ thick joint and a quality level $\mathrm{B}$, the most stringent requirement in [17]. It is noteworthy that partial penetration welds were performed with a purpose of emulating the common industrial practice of using a backing plate. Also, the welding conditions were repeated twice to verify process repeatability.

PWHT conditions were selected according to the recommended guidelines in [18] that stipulate cooling after welding to $95^{\circ} \mathrm{C}$ or below to ensure that the martensite phase completely transforms prior to retempering between $565^{\circ} \mathrm{C}$ and $620^{\circ} \mathrm{C}$. Hence, for PWHT in this study, each weld-cooled to room temperature after welding-was heated at a rate of $50^{\circ} \mathrm{C} / \mathrm{h}$ to $600 \pm 5^{\circ} \mathrm{C}$, followed by holding for $12 \mathrm{~h}$ and then furnace cooling.

To measure the longitudinal residual stress by means of the contour method, the welds were sectioned using wire EDM to extract two transverse halves, as detailed in [19-21]. The creation of these two new surfaces, shown in Figure 1(b), results in relaxation of the residual stresses and associated deformations of the partitioned planes. The displacement over these new surfaces were then measured using a confocal, white light, noncontact profilometer with $0.1 \mathrm{~mm}$ grid spacing, and a resolution of $0.06 \mu \mathrm{m}$ for the altitude and $2 \mu \mathrm{m}$ on the lateral displacements. After Gaussian filtering of the data, cubic splines with a $0.4 \mathrm{knot} /$ $\mathrm{mm}$ grid density were used to depict the surfaces and averaged to remove any effects of the shear component of stress, as discussed by Prime [20]. The resulting displacement data were then mapped on the applied FE mesh (Figure 1(c)), which consisted of 205,000 eight-node hexahedral elements with a side length of $1 \mathrm{~mm}$ and an aspect ratio of roughly one that gave a mesh-independent solution. The residual stresses normal to the sectioned face were then computed and mapped using an in-house elastic FE code that considered the bulk material behavior as isotropic and 
TABLE 1: As-received material heat treatment conditions prior to welding.

\begin{tabular}{|c|c|c|}
\hline Material & & ASTM A743 Grade CA6NM \\
\hline Heat treatments prior to welding & Double tempering* & $\begin{array}{r}1020^{\circ} \mathrm{C} \pm 10^{\circ} \mathrm{C} \text { for } 6 \mathrm{~h} \text { followed by air cooling to below } \\
\qquad M_{\mathrm{f}} \text { of } 90^{\circ} \mathrm{C}[13] \\
600^{\circ} \mathrm{C} \pm 20^{\circ} \mathrm{C} \text { for } 8 \mathrm{~h} \text { followed by air cooling to below } \\
M_{\mathrm{f}} \text { of } 90^{\circ} \mathrm{C} \\
580^{\circ} \mathrm{C} \pm 15^{\circ} \mathrm{C} \text { for } 8 \mathrm{~h} \text { followed by air cooling to room } \\
\text { temperature }\end{array}$ \\
\hline
\end{tabular}

${ }^{*}$ Double tempers are employed for CA6NM to meet the maximum requirement set by NACE of 23 HRC for castings intended for wet $\mathrm{H}_{2} \mathrm{~S}$ environments to mitigate the risk of stress corrosion cracking.

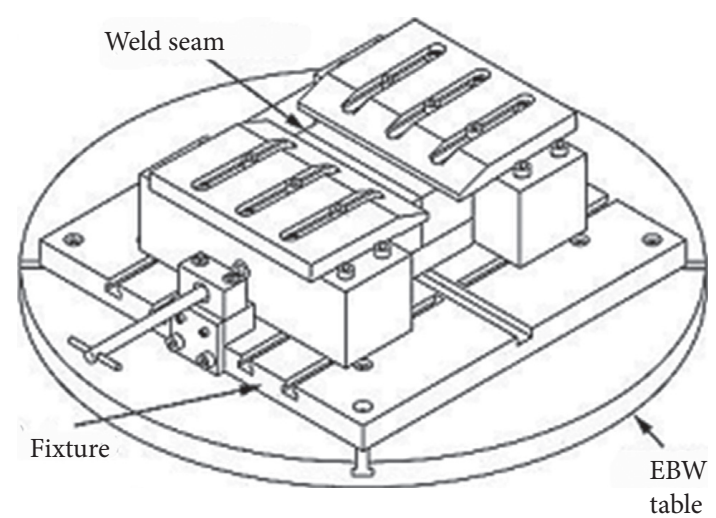

(a)



(b)

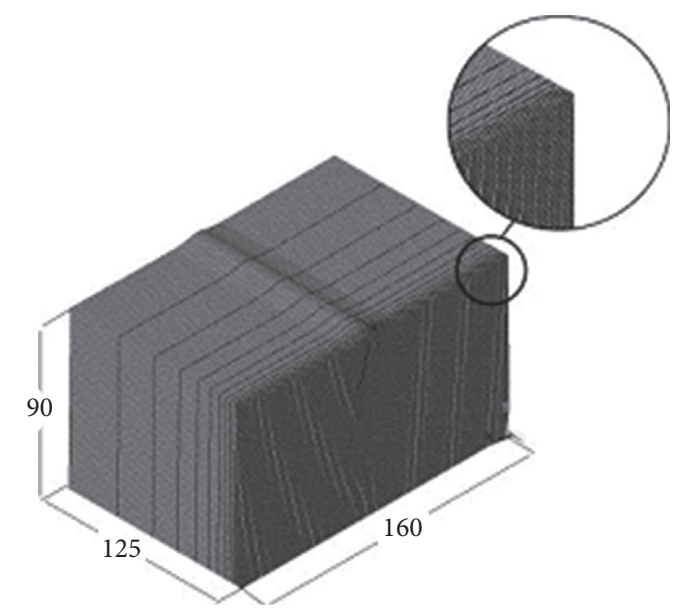

(c)

FIgure 1: (a) Clamping fixture mounted to the worktable of the EBW system. (b) First EDM cut sectioned transverse to the welding direction for measurement of the 2D longitudinal residual stress and (c) mesh applied for FE modeling (units in $\mathrm{mm}$ ).

linear elastic with a Young's modulus of $200 \mathrm{GPa}$ and a Poisson's ratio of 0.3 .

The top surfaces of the halved sections were cut, as shown in Figure 2(a). Then, to extract the samples for metallography (microscopy and microhardness) and mechanical testing (transverse and longitudinal tensile, Charpy impact, and bend), the welds were sectioned using EDM, as shown in Figure 2(b).

The metallographic sample was prepared and chemically etched with Vilella's reagent, as described in [21]. The FZ and HAZ were examined using optical microscopy (Olympus GX-71) at magnifications up to $1000 x$.
Vickers microhardness testing, according to [22] and detailed in [10], was performed using a Struers DuraScan machine with the ecos Workflow ${ }^{\mathrm{TM}}$ software module to obtain two-dimensional maps of the hardness distribution using a load of $500 \mathrm{~g}$, a dwell period of $15 \mathrm{~s}$, and interval spacing of $2 \mathrm{~mm}$.

For tensile mechanical property testing of welds in heavy sections, the recommended practice [23] for sampling is to extract multiple samples through the thickness. As shown in Figures 2(c) and 2(d), four transverse tensile samples (T1-T4) were extracted from a transverse cross section of the welds (Figure 2(c)) and six longitudinal tensile samples 




(a)

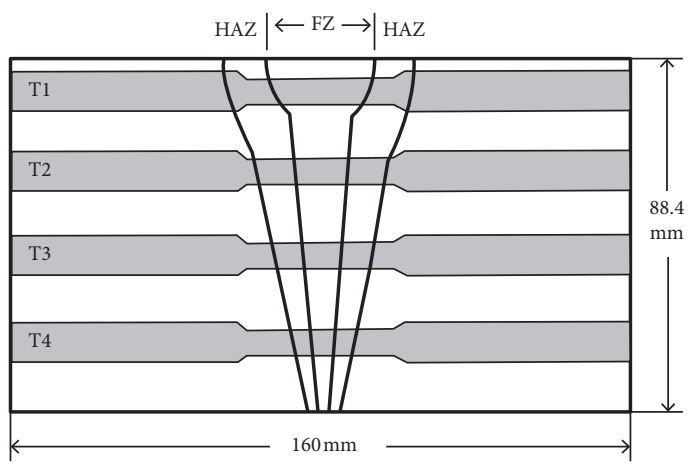

(c)

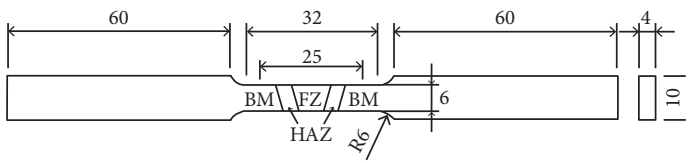

(e)

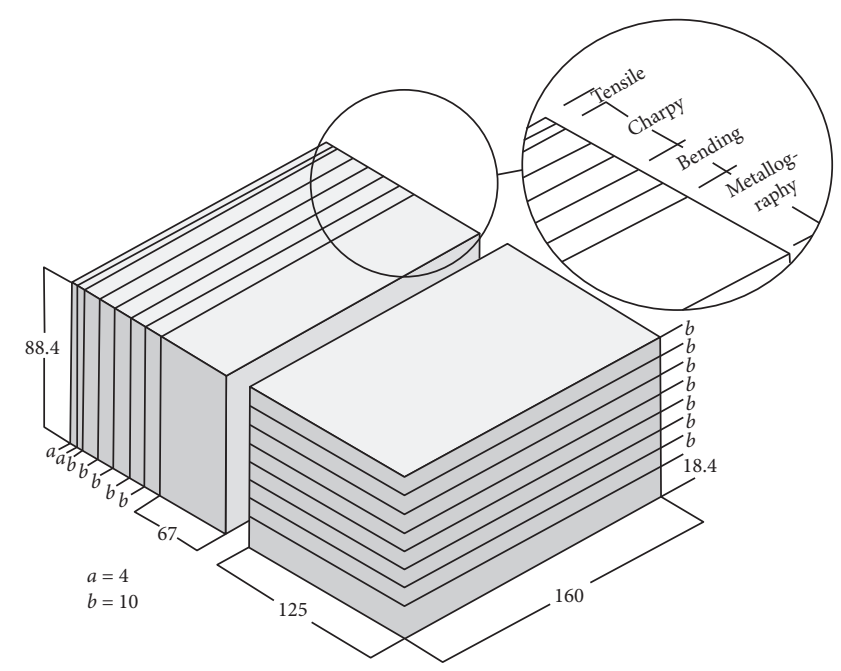

(b)

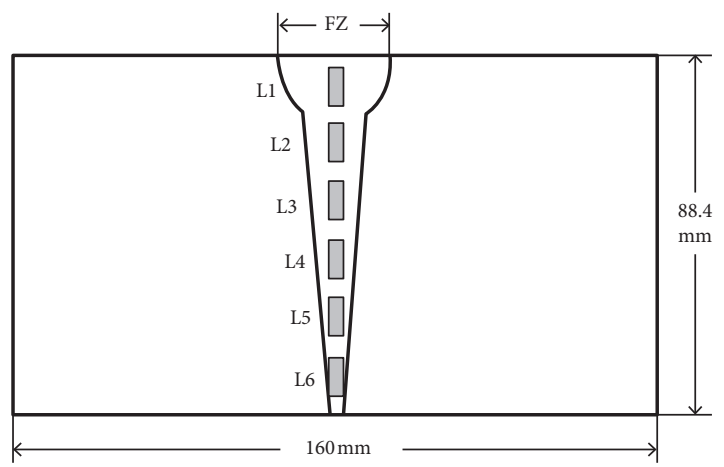

(d)

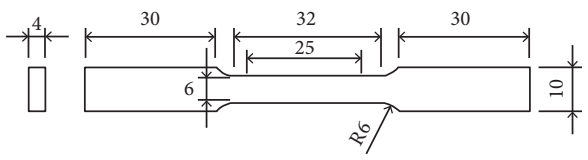

(f)

Figure 2: Schematic of the sampling steps after residual stress measurement: (a) top surface removal and (b) EDM to extract metallography, tensile, Charpy impact, and bend samples. Tensile sampling in the (c) transverse direction and the (d) longitudinal direction with the corresponding geometry for the (e) transverse and (f) longitudinal samples (units in $\mathrm{mm}$ ).

(L1-L6) were extracted parallel to the weld seam and in the FZ (Figure 2(d)). Figures 2(e) and 2(f) give the geometry of these two types of standard subsize tensile samples that were extracted from the EB welds and machined following the principles given in ASTM E8M-16a [24] for a GL of $25 \mathrm{~mm}$. To extract the longitudinal tensile samples from the FZ, the FZ was revealed by etching the polished weld sections in an aqueous solution of Vilella's reagent. In the case of the transverse samples, the relative fraction of the GL that consists of the FZ, ascribed as parameter FZ/GL, varied through the thickness of the weld. The FZ/GL ratio of each tensile sample was also determined using metallography to reveal the different microstructural regions (FZ, HAZ, and $\mathrm{BM})$. Both the transverse and longitudinal samples were tested at room temperature using a $250 \mathrm{kN}$ MTS testing frame integrated with a laser extensometer and a noncontact optical 3D deformation measurement system, Aramis ${ }^{\circledR}$ [25], as illustrated in Figure 3(a). Prior to tensile loading, the etched side of the sample was marked with two pieces of retroreflective tape to define the gage length for the laser extensometer measurements during testing (Figure 3(b)). On the opposite unetched side, the tensile sample surface was first painted with a white background and then a highcontrast random pattern of black speckles was applied (Figure 3(c)). As the functionality of the Aramis ${ }^{\circledR}$ system is sensitive to the quality of this speckle pattern, verification of pattern recognition was performed before tensile testing to ensure proper strain recording along the entire GL [26]. Tensile tests were conducted until rupture using displacement control at a rate of $2 \mathrm{~mm} / \mathrm{min}$. To obtain the global stress-strain curves and related mechanical properties, the load data collected from the tensile testing machine were used to calculate the engineering stresses during the test, while the related strains were calculated from the displacement obtained from the laser extensometer. The mechanical properties evaluated in this work included the YS 




(a)

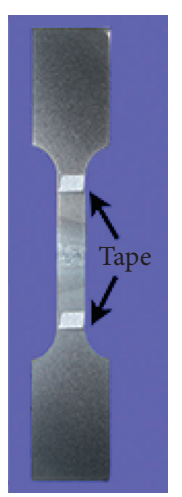

(b)

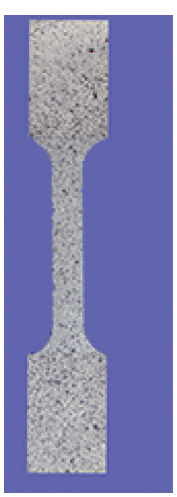

(c)

Figure 3: (a) MTS tensile testing configuration showing the position of the laser extensometer relative to the two CCD cameras of the Aramis ${ }^{\circledR}$ system, (b) etched side of the tensile sample showing the reflective tape applied to demarcate the gage length, and (c) opposite side of the tensile sample that was painted with a speckle pattern.

(0.2\% proof stress), UTS, and \%El obtained from the stressstrain curve of each tensile sample.

The deformation captured by the Aramis ${ }^{\circledR}$ system was used to map the 2D strain distribution along the GL of each tensile sample. Since the acquisition rate of the tensile machine and the laser extensometer $(50 \mathrm{~Hz})$ was different from the Aramis ${ }^{\circledR}$ system ( $2 \mathrm{fps}$ or $2 \mathrm{~Hz}$ ), synchronization of data was performed using an in-house code that matched the failure stage/point of the two strain acquisition systems and back-calculated the related stress data for each deformation stage recorded by the Aramis ${ }^{\circledR}$ system. In the end, the stressstrain curves obtained using the load data from the tensile machine with the strain data from the Aramis ${ }^{\circledR}$ system or the laser extensometer were compared to ensure corroboration between the two strain data sets. From the strain distribution maps captured using DIC, the strain localization just prior to rupture was examined. To extract values for the $\mathrm{YS}_{\mathrm{L}}$ in the different microstructural regions (FZ, HAZ, and BM) of the GL (Figure 2(c)), the local stress strain curves were plotted using the methodology described in [26]. After testing, the tensile fracture surfaces were observed using secondary electron imaging at $20 \mathrm{keV}$ on a Hitachi $3600 \mathrm{~N}$ SEM.

For Charpy $\mathrm{V}$-notch testing, sampling was undertaken in both the HAZ (CVNH1-CVNH3) and FZ (CVNF1-CVNF3) through the thickness, as shown in Figures 4(a) and 4(b), respectively. A $2 \mathrm{~mm}$ deep V-notch was then machined in the desired area (FZ or HAZ) of the Charpy samples (Figures $4(\mathrm{c})$ and $4(\mathrm{~d})$ ) that had final dimensions of $10 \mathrm{~mm} \times 10 \mathrm{~mm} \times 55 \mathrm{~mm}$, in accordance with the geometrical specifications given in ASTM E23-12c [27] and ASME Section VIII [28]. Charpy V-notch impact testing was carried out at $-18^{\circ} \mathrm{C}$ (a temperature requirement of $\mathrm{GE}$ Renewable Energy's specification for hydroelectric turbine manufacturing) using a Tinius Olsen pendulum impact machine (model IT 406) to evaluate the fracture toughness in the FZ and HAZ of the welds. The Charpy fracture tips and surfaces were then observed using OM and SEM.

The formability of the weld was assessed by three-point bend testing of two through-thickness cross-sections, extracted transverse to the weld seam (Figure 5), as described in [21] and in accordance with [23]. The tension side of each bend sample was observed visually using stereomicroscopy to examine the presence of any discontinuities that were assessed in accordance with [23].

\section{Results and Discussion}

3.1. Microstructure and Hardness Evolution in PWHTed CA6NM Joined by EBW. The BM microstructure of the asreceived CA6NM in the normalized and tempered conditions consisted predominately of tempered martensite laths (Figure 6(a)). Analysis of the other microstructural constituents using image analysis with optical microscopy and $\mathrm{XRD}$, as given in Table 2, indicated that residual levels of coarse primary $\delta$ stringers $(\sim 5 \%)$ from the steelmaking (casting) process and retained austenite (2.9\%)-typically at lath interfaces-were present in the BM. Heating during autogenous EBW, followed by solidification on cooling, led to the occurrence of different thermal cycles across the weldment and the formation of different metallurgically modified regions, namely, the FZ, HAZ, and BM. During heating, high temperature phases, such as austenite and $\delta$, formed in the weldment. Cooling to ambient temperatures after EBW led to reverse transformations in the weldment (Figures 6(b) and 6(c)) and the formation of "fresh" untempered martensite, hereafter referred to as retransformed martensite. Also, in the FZ, the presence of fine secondary $\delta$ $(\sim 5 \%)$ was observed in the interdendritic regions, and roughly $\sim 1.1 \%$ retained austenite-most likely present between the martensitic laths-was measured by XRD. Relative to the normalized and tempered conditions of the BM, the formation of untempered martensite in the weldment caused an increase in hardness in the FZ and HAZ, as illustrated in Figure 7. The average hardness values measured were $362.8 \pm 5.6 \mathrm{HV}$ and $388.7 \pm 5.7 \mathrm{HV}$ in the $\mathrm{FZ}$ and $\mathrm{HAZ}$, respectively. Also the occurrence of a maximum or peak hardness of $408 \mathrm{HV}$ was identified in the HAZ. The occurrence of a hardness peak in the HAZ is attributed to the dissolution of carbides in the high-temperature austenite phase that forms on heating during welding. On cooling, this 


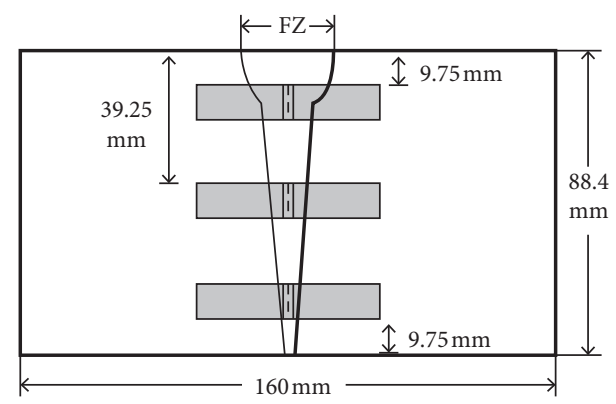

(a)

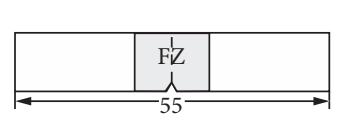

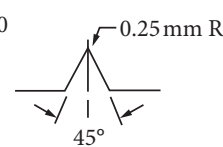

$45^{\circ}$

(c)

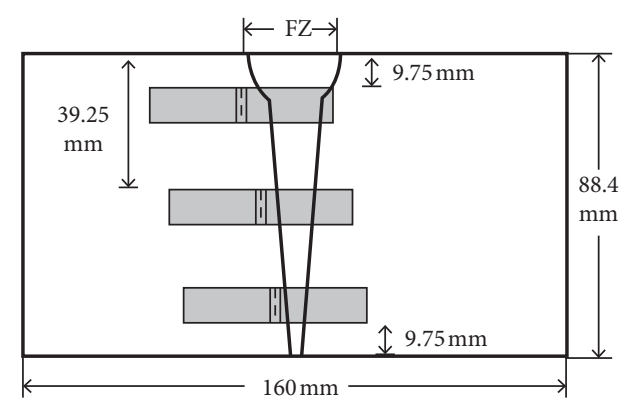

(b)
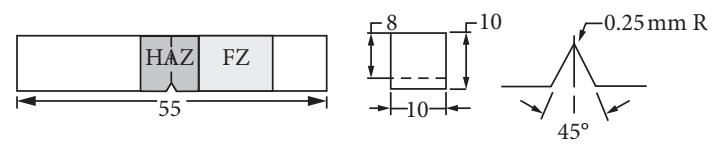

(d)

FIgURE 4: Charpy samples extracted with the V-notch root in (a) the FZ and (b) the HAZ with the corresponding geometry of the (c) FZ and (d) HAZ Charpy samples (units are in $\mathrm{mm}$ ).

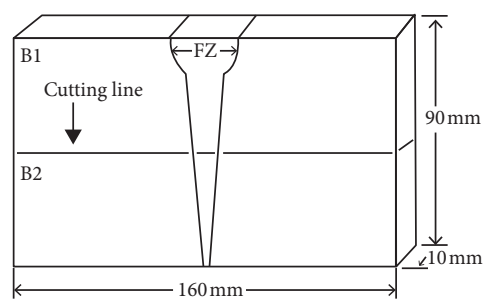

(a)

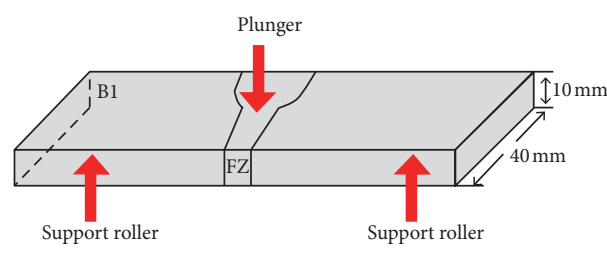

(b)

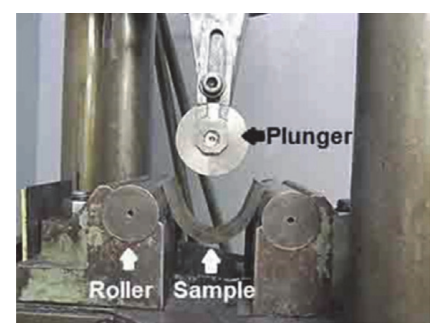

(c)

FIGURE 5: Three-point side bend test: (a) extraction of bend samples; (b) position of weld seam in the bend sample; (c) bend apparatus.
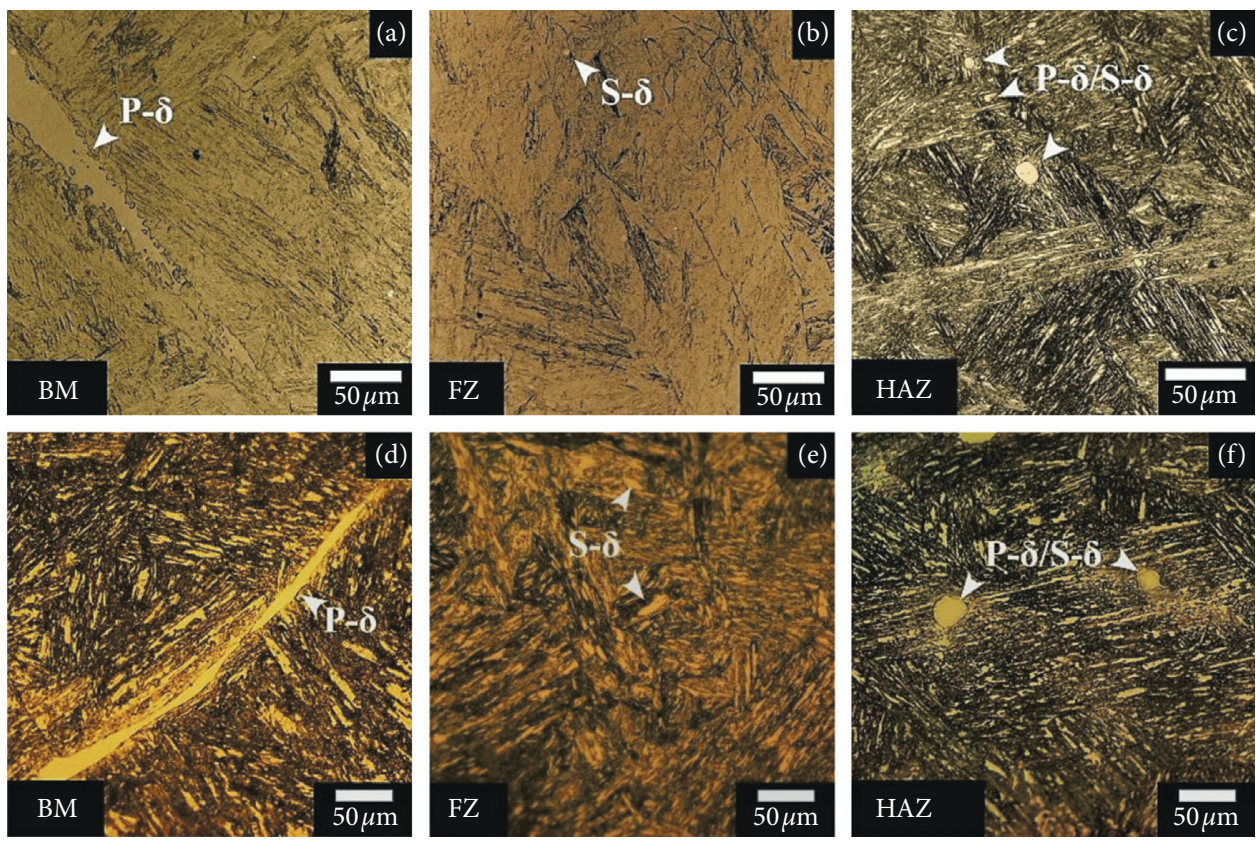

Figure 6: Microstructure of CA6NM in different regions of the EB welds (a) BM, (b) FZ, and (c) HAZ for the as-welded condition and (d) $\mathrm{BM}$, (e) FZ, and (f) HAZ for the PWHTed condition. 
TABLE 2: Microstructural characteristics of CA6NM before EBW, after EBW, and after PWHT.

\begin{tabular}{|c|c|c|c|}
\hline \multirow{2}{*}{ Zones } & \multicolumn{3}{|c|}{ Microstructural features } \\
\hline & Martensite & Retained austenite $^{*}(\%)$ & $\delta \mathrm{s}$ \\
\hline $\mathrm{BM}$ & $\begin{array}{l}\text { Predominate } \\
\text { Tempered }\end{array}$ & 2.9 & $\begin{array}{c}5 \% \\
\text { Coarse primary stringers }\end{array}$ \\
\hline As-welded FZ & $\begin{array}{l}\text { Predominate } \\
\text { Retransformed }\end{array}$ & 1.1 & $\begin{array}{c}5 \% \\
\text { Fine secondary, interdendritic }\end{array}$ \\
\hline PWHTed BM & $\begin{array}{l}\text { Predominate } \\
\text { Tempered }\end{array}$ & 22.4 & $\begin{array}{c}5 \% \\
\text { Coarse primary stringers }\end{array}$ \\
\hline PWHTed FZ & $\begin{array}{l}\text { Predominate } \\
\text { Tempered }\end{array}$ & 10.2 & $\begin{array}{c}5 \% \\
\text { Fine, interdendritic }\end{array}$ \\
\hline
\end{tabular}

* Presence between martensite lath is not resolvable using OM and/or SEM and fraction measured by XRD.

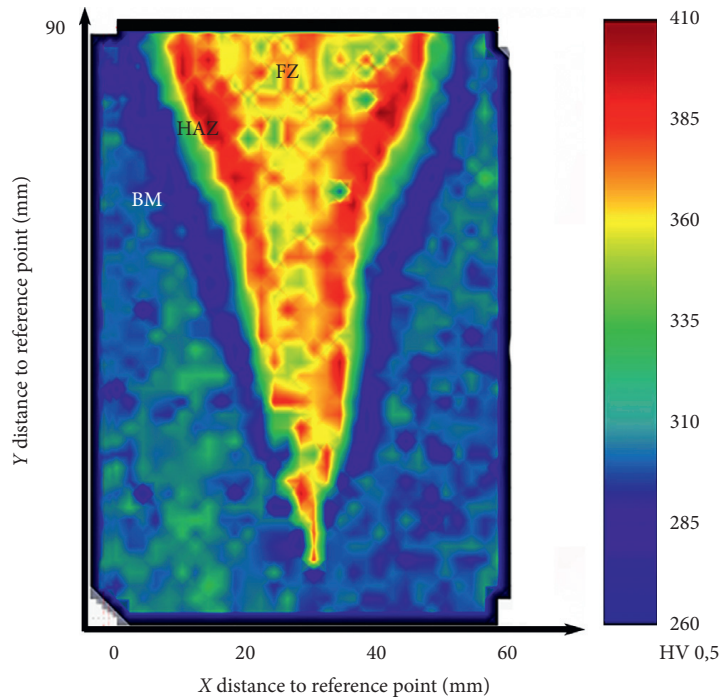

(a)

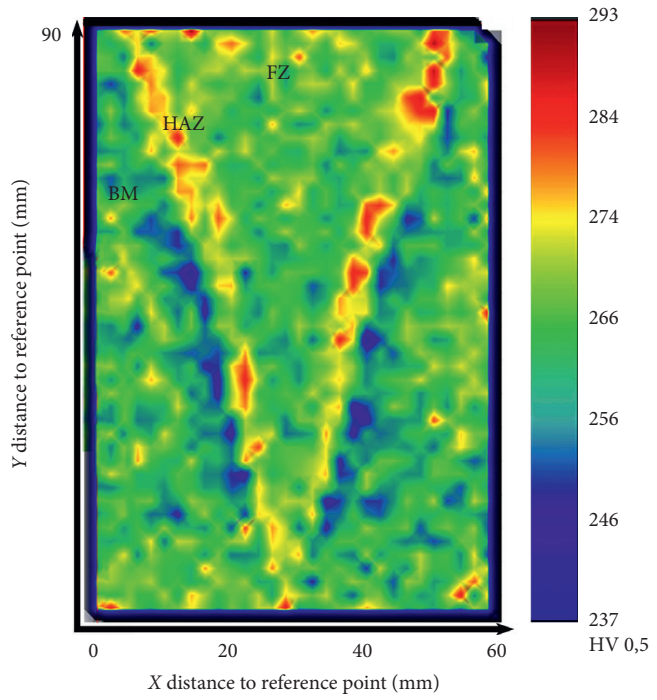

(b)

Figure 7: Hardness evolution in CA6NM EB welds without filler metal addition in (a) as-welded and (b) PWHTed conditions.

high carbon content austenite in the HAZ reverts to untempered martensite with a higher carbon content and gives rise to a peak hardness. Previously, for autogenous EBW of UNS S41500 stainless steel-the wrought equivalent to cast CA6NM-a similar trend of a lower hardness in the FZ $(\sim 365 \mathrm{HV})$ relative to a peak hardness in $\mathrm{HAZ}(\sim 400 \mathrm{HV})$ was reported in [8].

PWHT at $873 \mathrm{~K}\left(600^{\circ} \mathrm{C}\right)$ for 12 hours had the effect of reducing the hardness in the FZ and HAZ of the CA6NM EB welds, as illustrated in Figure 7. Specifically, after PWHT, the average hardness values measured were $269.2 \pm 6.8 \mathrm{HV}$ in the FZ and $277.2 \pm 6.7 \mathrm{HV}$ in the HAZ. Relative to the as-welded condition, the hardness decrease of $25.8 \%$ and $28.7 \%$ in the $\mathrm{FZ}$ and HAZ after PWHT is attributed to tempering of the retransformed martensite. Figures $6(\mathrm{~d})-6(\mathrm{f})$ illustrate the typical microstructures in the different regions of the weldment after PWHT that consisted predominately of retempered lath martensite. In the FZ, the characteristics and levels of secondary fine $\delta$ in the interdendritic regions remained similar after PWHT. Likewise, within the BM and HAZ, the primary and/or secondary $\delta$ (after EBW) were observed to have similar characteristics after PWHT due to the negligible changes in this phase during low temperature tempering $\left(600^{\circ} \mathrm{C}\right)$. By contrast, the retained austenite fraction (as measured by XRD) in the FZ (10.2\%) and BM (22.4\%) increased after PWHT. For this latter, during retempering above the Acl temperature of $\sim 580^{\circ} \mathrm{C}$, some martensite in the microstructure would partially transform to austenite (often referred to as reversed austenite). Hence, during holding for $12 \mathrm{~h}$ at $600^{\circ} \mathrm{C}$, an increasing quantity of reversed austenite can be stabilized and, during cooling, be retained at room temperature through a mechanism described as anomalous phase transformation that is driven by a nonuniform distribution of solute concentration and the existence of local stresses in the martensite $[29,30]$. As austenite is softer than martensite, an increasing fraction of the former phase in the microstructure leads to further softening of the BM after retempering.

3.2. Global and Local Properties from Static Tensile Loading of PWHTed CA6NM. The global tensile properties (YS, UTS, and \%El) of CA6NM were measured after PWHT using 
TABLE 3: Global tensile properties and failure locations for CA6NM samples.

\begin{tabular}{|c|c|c|c|c|c|c|c|c|}
\hline Sample & Direction & $\begin{array}{l}\text { FZ/ } \\
\text { GL }\end{array}$ & Failure location & Regions in GL & YS (MPa) & UTS (MPa) & $\mathrm{El}(\%)$ & $\begin{array}{c}\text { Joint } \\
\text { efficiency }\end{array}$ \\
\hline L1-L6 & Longitudinal to EB weld seam & 1 & FZ & FZ & $721.6 \pm 13.0$ & $794.1 \pm 1.5$ & $22.2 \pm 2.8$ & 1.05 \\
\hline $\mathrm{T} 1$ & & 0.9 & FZ & $\mathrm{FZ}+\mathrm{HAZ}$ & 730.9 & 801.6 & & 1.06 \\
\hline $\mathrm{T} 2$ & & 0.45 & HAZ & $\mathrm{FZ}+\mathrm{HAZ}$ & 737.7 & 796.7 & & 1.06 \\
\hline T3 & Transverse to EB weld seam & 0.35 & $\mathrm{BM}$ & $\mathrm{FZ}+\mathrm{HAZ}+\mathrm{BM}$ & 688.7 & 794.9 & $18.2 \pm 1.1$ & 1.05 \\
\hline $\mathrm{T} 4$ & & 0.2 & $\mathrm{BM}$ & $\mathrm{FZ}+\mathrm{HAZ}+\mathrm{BM}$ & 691.6 & 796.8 & & 1.06 \\
\hline CA6NM [12] & $\mathrm{N} / \mathrm{A}$ & $\mathrm{N} / \mathrm{A}$ & $\mathrm{N} / \mathrm{A}$ & N/A & 550 & 755 & 15 & N/A \\
\hline
\end{tabular}

various tensile samples extracted through the thickness of the autogenous EB welds in the longitudinal (L1-L6) and transverse (T1-T4) directions. The values of these properties, as well as the FZ/GL ratio and failure location, are reported in Table 3. The joint efficiency-ratio between the UTS of the welded joint to that of the BM $(755 \mathrm{MPa})$-that was calculated for both the longitudinal and transverse tensile sample types indicated equivalent static tensile strengths for the CA6NM EB butt welds after PWHT relative to the requirements for the BM.

The acceptance criteria for welded CA6NM, as given in ASME Section IX [23], stipulates a UTS of at least $5 \%$ above the minimum UTS of the BM (or $>793 \mathrm{MPa}$ ) and tensile failure in the BM of the weld. In both the longitudinal and transverse directions, the tensile strength of the autogenous CA6NM EB welds after PHWT met this minimum requirement. However, the failure location was different for specific samples (L1-L6 and T1-T2) and reasoned on the basis of the FZ/GL ratio through the constituents (FZ, HAZ, and $\mathrm{BM}$ ) present in the GL of each of these samples. For instance, all the longitudinal samples (L1-L6) failed in the FZ because the entire GL comprised the FZ only (FZ/GL ratio of 1 ). In the case of the T1 sample that had a FZ/GL ratio of 0.9 , the GL comprised mostly of the FZ (at the center) with a minor presence of the HAZ (at both peripheries). In the absence of the softer $\mathrm{BM}$ region in the GL, strain localization and failure during tensile loading of T1 was observed to occur in the FZ, as illustrated in Figure 8(a). This corresponds well with the observed hardness evolution (Figure 7) from the FZ $(265-275 \mathrm{HV})$ to the FZ/HAZ boundary $(290 \mathrm{HV}$ peak), in which the FZ is the softest region. By contrast, the $\mathrm{T} 2$ sample, with a $\mathrm{FZ} / \mathrm{GL}$ ratio of 0.45 and a GL also consisting of a central FZ and a HAZ at each periphery, failed in the HAZ. In the T2 sample, there is a higher fraction of HAZ in the GL. Hence, regions close to the HAZ/BM boundary (Figure 7$)$ that are softer $(\sim 260 \mathrm{HV})$ than the FZ (265-275 HV) are present in the GL. During tensile loading, strain localization and tensile failure in T2 are thus observed to occur in the softest region of the HAZ, as illustrated in Figure 8(b). Finally, for samples T3-T4, the GL comprised all three constituents in a typical weld: FZ, $\mathrm{HAZ}$, and BM. In this case, strain localization and tensile failure occurred consistently in the BM (Figures 8(c) and $8(\mathrm{~d}))$, the softest region $(\sim 245 \mathrm{HV})$ in the PWHTed CA6NM welds.

From a perspective of material design allowable data for CA6NM EB welds after PWHT, the global tensile properties measured from samples T3-T4 are representative of the entire welded assembly, due to the sampling of each characteristic region-FZ, HAZ, and BM-in the weldment. Overall, these tensile properties for the PWHTed CA6NM EB welds corroborate well with those reported previously $[21,31]$ for low-carbon $13 \% \mathrm{Cr}-4 \% \mathrm{Ni}$ martensitic stainless steel grades, including UNS S41500, as tabulated in Table 4. The differences in tensile properties between PWHTed CA6NM and UNS S41500 can be attributed, for instance, to differences in chemistry (particularly, the carbon content) of the alloys and heat treatment conditions (normalizing and tempering temperature and time).

To comprehensively understand the effect of the different regions in the CA6NM EB welds on the mechanical performance after PWHT, the values for $\mathrm{YS}_{\mathrm{L}}$ (Table 5) in the FZ, HAZs, and BM were determined for samples T1 to T4 from their strain distribution maps of the gage area just before rupture (Figure 8). Specifically, in these strain maps, the region of strain concentration, indicated as the area with the highest intensity, corresponds to the location of the fracture that occurred immediately afterward. For each transverse tensile sample, the strain distribution map (Figures 8(a)-8(d)) revealed strain inhomogeneity and localization in the region of final fracture with significantly lower plastic deformation in the remaining areas of the gage section. Accordingly, notwithstanding the average global strain value of $18 \%$ (Table 4 ) for samples $\mathrm{T} 1-\mathrm{T} 4$, the maximum local strains in the area of failure ranged from $26 \%$ to $32 \%$ (Figures $8(\mathrm{a})-8(\mathrm{~d})$ ). In the case of $\mathrm{T} 1$, where failure occurred in the $\mathrm{FZ}\left(\mathrm{YS}_{\mathrm{L}}=727.7 \mathrm{MPa}\right)$ at a strain of $32 \%$ locally, Figure 8 (a) gives evidence for the very low straining $(<4 \%)$ in the higher strength HAZ areas $\left(\mathrm{YS}_{\mathrm{L}}=738.8 \mathrm{MPa}\right)$ in the gage section. Similarly, in the T2 sample, the high strength regions of the gage section comprising the $\mathrm{FZ}\left(\mathrm{YS}_{\mathrm{L}}=728.4 \mathrm{MPa}\right)$ and the adjacent $\mathrm{HAZ}$ $\left(\mathrm{YS}_{\mathrm{L}}=741.3 \mathrm{MPa}\right)$ areas exhibited very low strains $(2-6 \%)$ locally, whilst in the softest region of the HAZ $\left(\mathrm{YS}_{\mathrm{L}}=718.0 \mathrm{MPa}\right)$ near the $\mathrm{BM}$, the local strains reached $26 \%$ before failure. In both the T3 and T4 samples, the GL comprised of all three constituents (FZ, HAZ, and BM) of the $\mathrm{EB}$ weld and failed in the softest $\mathrm{BM}$ region $\left(\mathrm{YS}_{\mathrm{L}}=663.2 \mathrm{MPa}\right)$ that exhibited local strains of $\sim 28 \%$ just before failure. In comparison, the FZ and HAZ in T3 and T4 had local strains of less than $9 \%$. Overall, the average $\mathrm{YS}_{\mathrm{L}}$ in the FZ and $\mathrm{BM}$ was calculated to be $727.2 \mathrm{MPa}$ and 663.2 $\mathrm{MPa}$, respectively. For the HAZ, in the region of peak hardness, the highest average $\mathrm{YS}_{\mathrm{L}}$ value of $740.1 \mathrm{MPa}$ was observed, whilst the average $\mathrm{YS}_{\mathrm{L}}$ closer to the $\mathrm{BM}$ was $712.0 \mathrm{MPa}$. It is noteworthy that the average $\mathrm{YS}_{\mathrm{L}}$ measured 




(a)

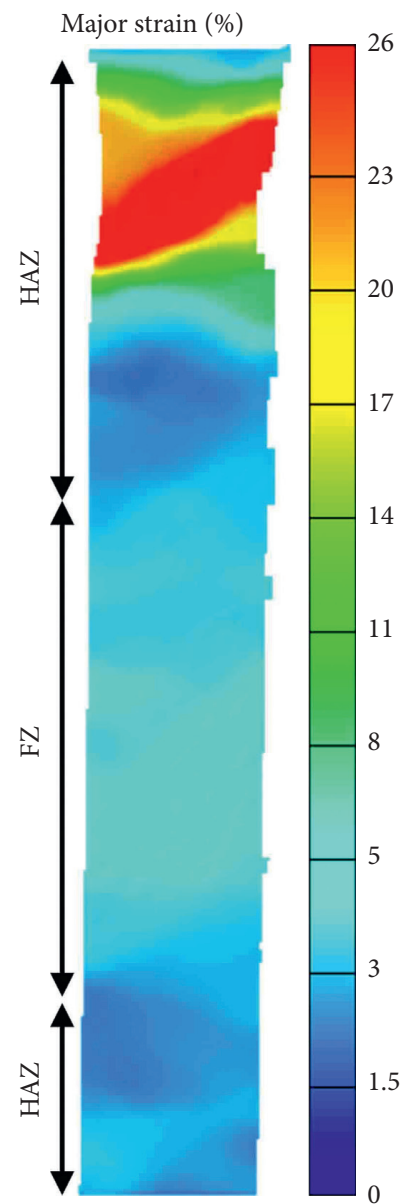

(b)

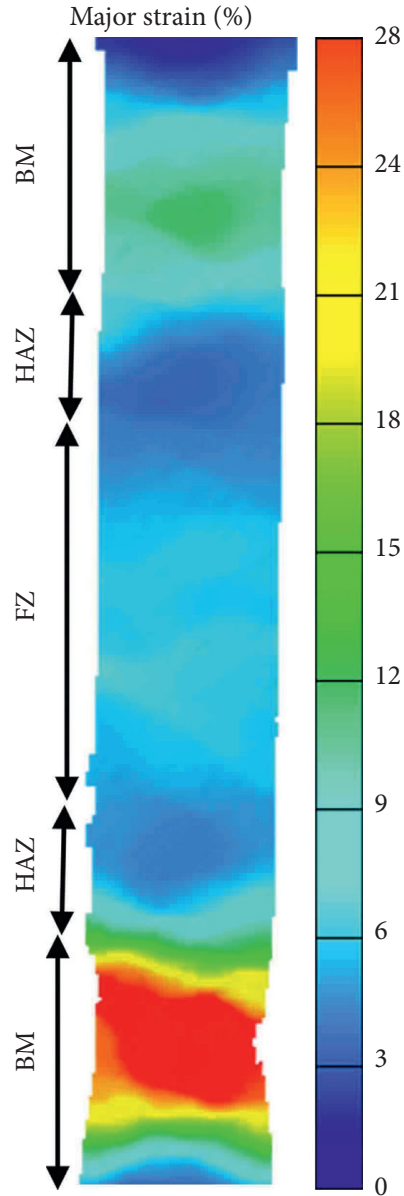

(c)

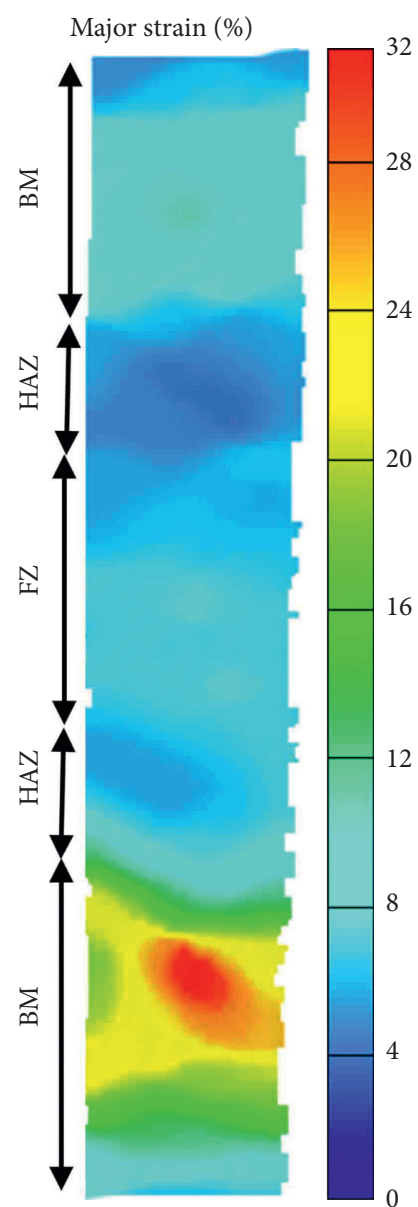

(d)

Figure 8: Strain distribution maps before rupture in transverse tensile samples: (a) T1; (b) T2; (c) T3; (d) T4.

TABLe 4: Comparison of the tensile properties and failure locations for PWHTed CA6NM and UNS S41500*.

\begin{tabular}{lcccccc}
\hline Process & Material & Thickness $(\mathrm{mm})$ & YS $(\mathrm{MPa})$ & UTS (MPa) & El (\%) & Failure location \\
\hline \multirow{2}{*}{ EBW } & CA6NM & 90 & 691.6 & 796.8 & 18.2 & BM \\
HLAW & UNS S41500 [21] & 90 & 777.3 & 862.3 & 17.0 & - \\
\hline
\end{tabular}

${ }^{*}$ FZ/GL ratio of 0.2 and GL consisting of BM, HAZ, and FZ.

TABLE 5: $\mathrm{YS}_{\mathrm{L}}(\mathrm{MPa})$ for PWHTed CA6NM samples having different FZ/GL ratios.

\begin{tabular}{|c|c|c|c|c|c|}
\hline Sample & T1 FZ/GL = 0.9 & $\mathrm{~T} 2 \mathrm{FZ} / \mathrm{GL}=0.45$ & $\mathrm{~T} 3 \mathrm{FZ} / \mathrm{GL}=0.35$ & $\mathrm{~T} 4 \mathrm{FZ} / \mathrm{GL}=0.2$ & Average $\mathrm{YS}_{\mathrm{L}}(\mathrm{MPa})$ \\
\hline$\overline{F Z}$ & $727.7^{*}$ & 728.4 & 725.5 & 727.1 & 727.2 \\
\hline $\mathrm{HAZ}_{\mathrm{FZ}} * *$ & 738.8 & 741.3 & 739.8 & 740.1 & 740.1 \\
\hline $\mathrm{HAZ}_{\mathrm{BM}}{ }^{* * *}$ & - & $718.0^{*}$ & 706.0 & 711.9 & 712.0 \\
\hline $\mathrm{BM}$ & - & - & $663.0^{*}$ & $663.3^{*}$ & 663.2 \\
\hline
\end{tabular}

${ }^{*}$ Region of strain localization and failure; ${ }^{* *}$ region of peak hardness in HAZ close to FZ; ${ }^{* * *} \mathrm{HAZ}$ just adjacent to BM.

for the $\mathrm{FZ}(727.2 \mathrm{MPa})$ region in the gage area of samples T1-T4 using the DIC methodology are in good agreement with the average global YS measured from samples L1-L6 $(721.6 \mathrm{MPa})$ that comprised entirely of the FZ. The corroboration of this data validates the applicability of the DIC methodology and the accuracy of the resulting mechanical properties measured for the distinct regions in the CA6NM EB welds after PWHT.

After static tensile loading, the fracture surfaces of the longitudinal and transverse samples were examined at low and high magnifications using SEM (Figures 9 and 10). For the longitudinal tensile samples that comprised entirely of 

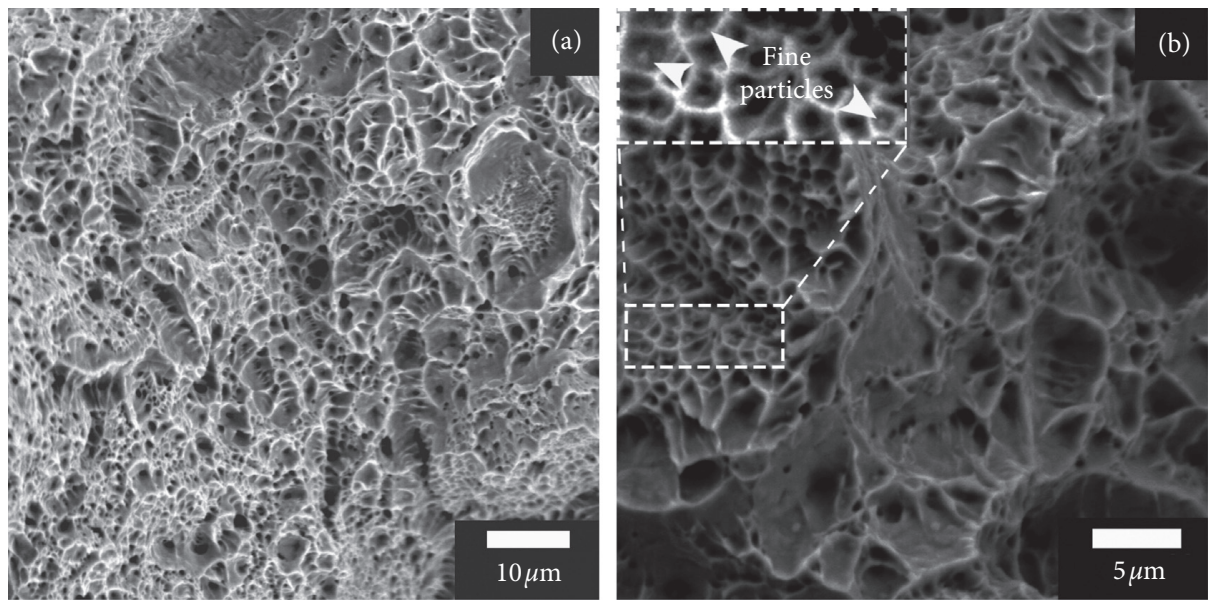

FIGURE 9: Representative SEM images of the fracture surface from the longitudinal (L1-L6) tensile samples of PWHTed CA6NM that failed in the FZ.
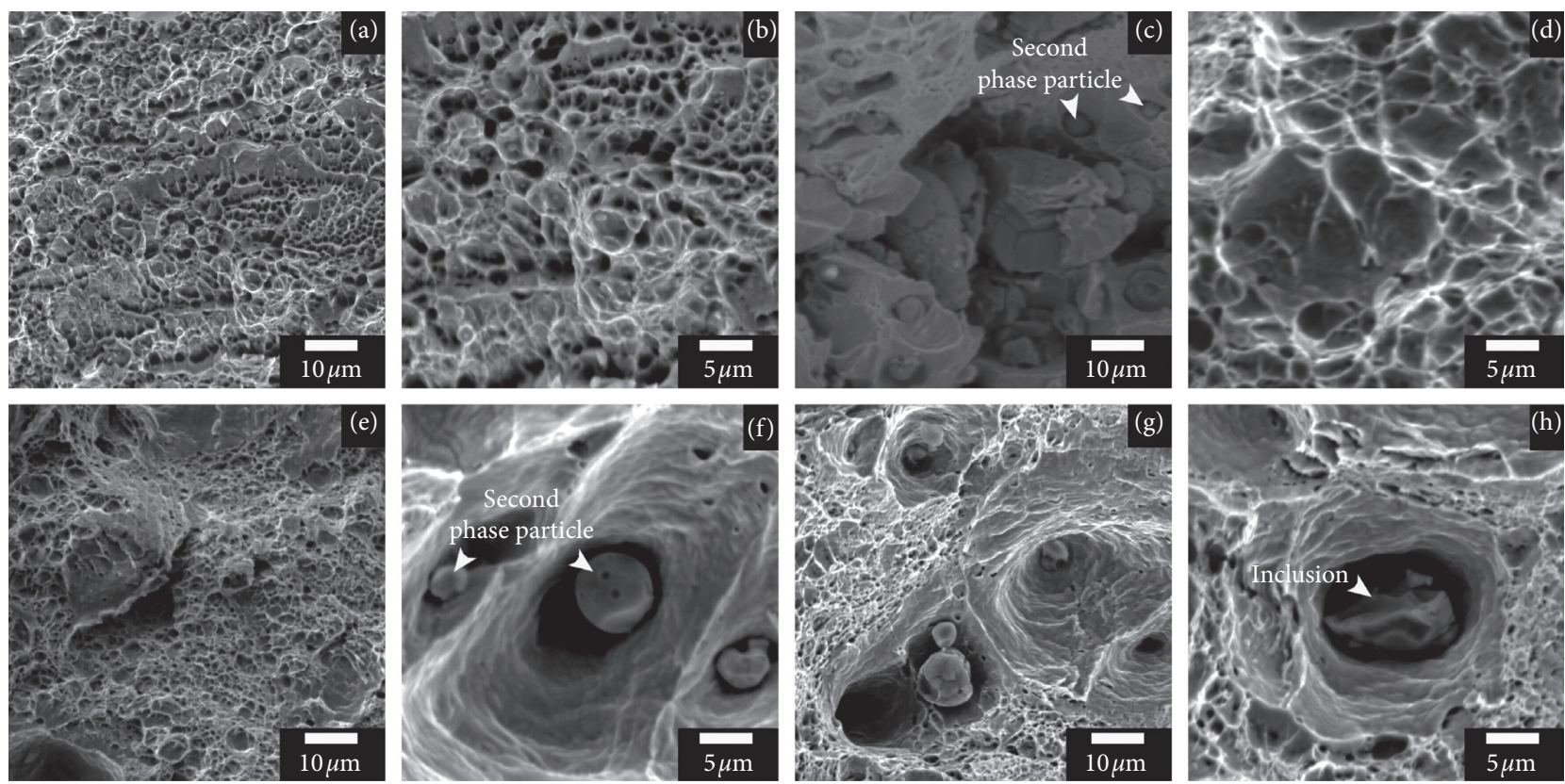

Figure 10: SEM images of the fracture surfaces from the transverse tensile samples of PWHTed CA6NM: (a, b) T1 (failed in FZ); (c, d) T2 (failed in HAZ); (e, f) T3 (failed in BM); (g, h) T4 (failed in BM).

the $\mathrm{FZ}$, the fracture surface characteristics were typical of ductile failure with the presence of fine dimples (Figures 9(a) and 9(b)) formed by the void nucleation and coalescence mechanism. These dimpled fracture surface characteristics were also observed for the T1 sample-that consisted primarily of the FZ (FZ/GL ratio of 0.9) - as tensile failure occurred in the FZ (Figures 10(a)-10(b)). By contrast, the T2-T4 samples (Figures 10(c)-10(h)) that failed in the BM (or in its proximity) demonstrated ductile fracture surfaces but with a combination of coarse and fine dimples. These dimples were typically associated with the presence of inclusions and/or second phase particles, as evident in the higher magnification images shown in Figure 10. Thus, during tensile loading of the PWHTed EB welds, microvoids initiated through decohesion between the martensitic matrix and these particles/inclusions and/or rupture of the particles/inclusions. Overall, the failure mechanisms describing fracture initiation (microvoids), propagation (void coalescence), and rupture (cracking) for the PWHTed CA6NM EB welds are in good agreement with the observations reported for PWHTed CA6NM welds joined by HLAW [31] and PWHTed UNS S41500 EB welds [21].

It is well known that the stress, and, accordingly the strain, to nucleate microvoids decreases with increasing particle size [32]. Accordingly, the larger second phase particles/inclusions in the microstructure (e.g., coarse primary $\delta$ in Figures $6(\mathrm{a})$ and $6(\mathrm{~d}))$ of the BM relative to the FZ (e.g., fine secondary $\delta$ in Figures 6(b) and 6(e)) could explain the lower global (18\%) and local (26-28\%) fracture strains in the former compared to the latter that fractured at $22 \%$ 
(global) and 32\% (local), respectively. These findings demonstrate the high integrity and performance of the FZ microstructure of the EB welds in the PWHTed (tempered) condition relative to the properties of the tempered CA6NM casting, which typically exhibits defects (cavities and inclusions) remnant from the casting process [33].

\subsection{Charpy V-Notch Impact Characteristics of the FZ and HAZ} after $P W H T$. From the Charpy V-notch tests undertaken at $-18^{\circ} \mathrm{C}$ on the $\mathrm{FZ}$ and $\mathrm{HAZ}$, the impact energies and failure locations were measured for the CA6NM EB welds in the PWHTed condition, as given in Table 6. The average Charpy $\mathrm{V}$-notch impact energy values in the FZ $(63.3 \pm 4.6)$ and HAZ $(148 \pm 18.0)$ of the CA6NM EB welds in the PWHTed condition (Table 7) superseded the minimum requirements of $27 \mathrm{~J}$ specified in ASME Section VIII, Div. 1 [28].

Relative to as-welded CA6NM, PWHT was effective in doubling the impact energy in the hardest region (FZ) of the EB welds, as compared in Table 7. The higher impact toughness measured for the FZ and HAZ after PWHT can be attributed to a reduction in the dislocation density and internal (residual) stresses (as described below) in the EB welds that occurred due to tempering of the retransformed martensite in the microstructure of the FZ and HAZ, as well as the formation of reversed austenite during prolonged holding for 12 hours at $600^{\circ} \mathrm{C}$. Specifically, it has been reported that the reversed austenite transforms to martensite (stress-induced transformation) during impact loading and acts as a shock absorber that reduces the energy available for crack propagation [34,35]. The transformation of reversed austenite to martensite has been reported to occur through the mechanism of transformation-induced plasticity that has been associated with high-toughness properties [29].

It is noteworthy that PWHT enabled qualifying the CA6NM EB welds to surpass the more stringent impact energy specification of $34 \mathrm{~J}$ at $-18^{\circ} \mathrm{C}$ set by GE Renewable Energy [18] for their hydroelectric turbine manufacturing, which could not be met in the as-welded condition. Also, the improved impact performance findings validate that the selection of the thermal conditions (temperature and time) and procedure for PWHT from ASME Section IX are applicable for heavy gage ( $90 \mathrm{~mm}$ thick) EB welds in CA6NM. Finally, considering the comparable impact properties of CA6NM welds joined using high energy/power density technologies, as given in Table 7, the EBW process has advantages over HLAW of reduced operational costs (no groove preparation, filler metal addition, or high purity gas shielding), significantly higher penetration capacity as well as healthier/safer working environment (no emissions or ozone generation).

The fracture tips and surfaces in the FZ and HAZ for two representative Charpy samples-CVNF2 and CVNH2-were examined using OM and SEM at different magnifications, as shown in Figure 11. For cracking initiated in the FZ during impact loading (CVNF2 sample), the OM image of the fracture tip, as given in Figure 11(a), showed no evidence of crack path deviation to the HAZ. Propagation of the initiated crack appeared to advance from the notch through the tempered martensitic structure of the FZ (Figure 11(b)). The fracture
TABLE 6: Charpy V-notch impact properties in FZ and HAZ of PWHTed EB welds tested at $-18^{\circ} \mathrm{C}$.

\begin{tabular}{lccc}
\hline Sampling ID & Notch location & $\begin{array}{c}\text { Impact energy (J) } \\
\text { CA6NM }\end{array}$ & $\begin{array}{c}\text { Failure } \\
\text { location }\end{array}$ \\
\hline CVNF1 & FZ & 68 & FZ \\
CVNF2 & FZ & 57 & FZ \\
CVNF3 & FZ & 65 & FZ \\
\hline CVNH1 & HAZ & 156 & HAZ \\
CVNH2 & HAZ & 127 & HAZ \\
CVNH3 & HAZ & 160 & HAZ \\
\hline
\end{tabular}

TABLE 7: Comparison of the average Charpy impact energies (J) for CA6NM.

\begin{tabular}{|c|c|c|c|c|}
\hline Condition & Process & $\begin{array}{c}\text { Section } \\
\text { thickness }(\mathrm{mm})\end{array}$ & $\mathrm{FZ}$ & HAZ \\
\hline \multirow{2}{*}{$\begin{array}{l}\text { PWHTed } \\
\left(600^{\circ} \mathrm{C}\right) \\
\text { As-welded [10] }\end{array}$} & \multirow[t]{2}{*}{$\mathrm{EB}$} & \multirow[t]{2}{*}{90} & $63.3 \pm 4.6$ & $148 \pm 18.0$ \\
\hline & & & $29.0 \pm 4.4$ & $113 \pm 15.4$ \\
\hline \multirow{2}{*}{$\begin{array}{l}\text { PWHTed } \\
\left(600^{\circ} \mathrm{C}\right)[31] \\
\text { As-welded [36] }\end{array}$} & \multirow[t]{2}{*}{ HLAW } & \multirow[t]{2}{*}{10} & 45.5 & N/A \\
\hline & & & 28.5 & N/A \\
\hline $\begin{array}{l}\text { ASME Section } \\
\text { VIII Div. } 1 \text { [28] }\end{array}$ & N/A & N/A & & $\geq 27$ \\
\hline $\begin{array}{l}\text { GE Renewable } \\
\text { Energy [37] }\end{array}$ & N/A & N/A & & $\geq 34$ \\
\hline
\end{tabular}

surface consisted predominately of cleavage facets (Figure 11(c)). But, fractography, at higher magnifications, also revealed necklace-like structures of fine dimples clustered around these facets (Figures 11(d)). Thus, though the primary fracture mode for the CVNF2 sample-notched (and failed) in the FZ - was quasi-cleavage, the presence of these dimples gives evidence for the concomitant occurrence of secondary ductile failure mechanisms in the FZ during impact loading.

By contrast, there was greater evidence of crack path deviation during impact loading of the Charpy samples notched in the HAZ, as seen in Figure 11(e) for CVNH2. From the OM images of the fracture tip, the initiated crack (in the HAZ) propagated somewhat in the direction of the HAZ/ FZ boundary (Figure 11(e)) and the crack path consisted of fractured $\delta$ particles, as well as voids nucleated at $\delta /$ martensite interfaces (Figure 11(f)). However, final failure of this initiated crack remained within the HAZ. Overall, there was strong evidence of considerable plastic deformation in the HAZ with the dimples on the fracture surface being indicative of failure occurring predominately through microvoid nucleation, growth, and coalescence (Figures $11(\mathrm{~g})$ and 11(h)). The ductile fracture mode in the HAZ (CVNH2) compared to the mixed brittle (cleavage) and ductile fracture mechanisms in the FZ concur well the higher impact energies measured for the former, as given in Tables 6 and 7 for the EB welded CA6NM after PWHT.

3.4. Bend Test Results of EB Welded CA6NM after PWHT. For quality control, side bending testing of butted joints is typically used to quantitatively assess the weld ductility and integrity so as to ensure manufacturing consistency. During 
$\mathrm{OM}$
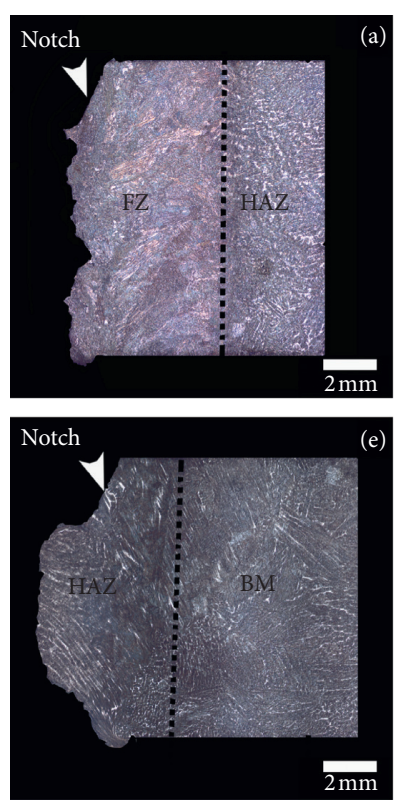

$\mathrm{OM}$
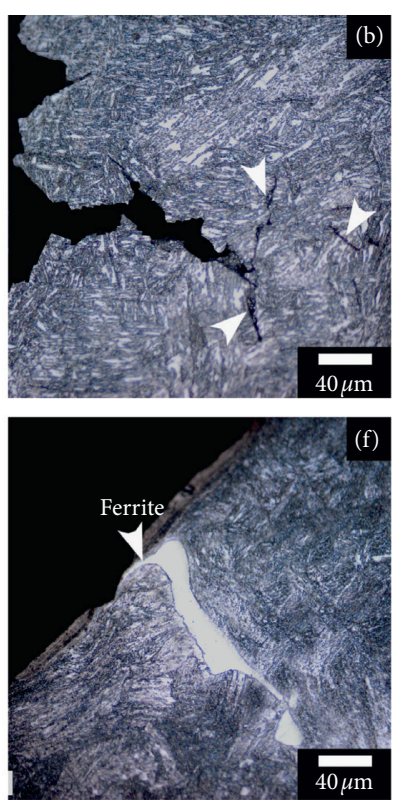

SEM


SEM
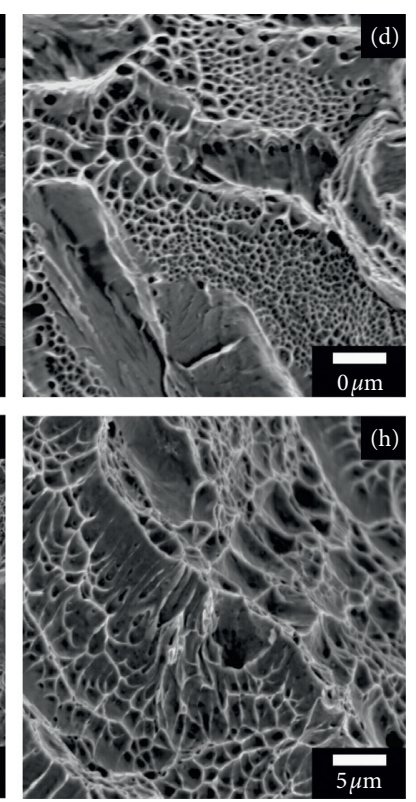

Figure 11: Representative images of the Charpy impact fracture tips and surfaces for PWHTed CA6NM in (a-d) FZ (CVNF2 samples) and (e-h) HAZ (CVNH2 samples).

side bending, the outer bend surface plastically deforms in tension and any discontinuities present in the weld can be revealed. Figure 12(a) schematically illustrates side bending of a transverse face specimen, which is particularly suited for revealing lack of fusion defects on the side wall or at the root, as well as any possibility of premature failure in the high hardness (more brittle) regions of the FZ and HAZ. To test the full weld thickness, two halves of an EB welded transverse cross section were side bend tested. After bending, the outer surfaces of the specimens were examined using stereomicroscopy to identify any discontinuities/defects that may have opened on the tensile face. According to the specifications in ASME Section IX [23], an open defect that exceeds $3.2 \mathrm{~mm}$ in length in the FZ or HAZ on the convex (tension) face is a cause for weld rejection. As revealed in Figure 12(b), the PWHTed EB welds in CA6NM exhibited uniform and adequate bending across both transverse faces (i.e., covering the entire joint thickness) without the manifestation of any discontinuities, thereby meeting the acceptance criteria of ASME Section IX [23]. Hence, the FZ and HAZ of the EB weld in CA6NM after PWHT are qualitatively integral, ductile, and adequately bonded.

\subsection{Residual Stress Distribution in EB Welded CA6NM after} $P W H T$. After PWHT, the longitudinal residual stresses through the thickness of the CA6NM EB weld were distributed, as shown in Figure 13, with maximum tensile and compressive stresses of $\sim 100 \mathrm{MPa}$ occurring in the HAZ and FZ, respectively. The compressive residual stresses in the FZ of the $\mathrm{EB}$ weld may be attributed to the low transformation temperature of the martensite phase $\left(M_{\mathrm{s}}\right.$ of $270^{\circ} \mathrm{C}$ and $M_{\mathrm{f}}$ of $90^{\circ} \mathrm{C}$ ) in $13 \% \mathrm{Cr}-4 \% \mathrm{Ni}$ martensitic stainless steels. In particular, during cooling after welding of CA6NM, the low temperature transformation of austenite-to-martensite comes with significant increases in the specific volume. This volumetric expansion then contributes significantly towards the development of compressive residual stresses and can compensate for the tensile residual stress transpiring from the accumulated thermal contraction strains due to EBW [38]. As the authors observed previously for as-welded CA6NM [11], the core FZ region in the heavy section weld can thus develop very high compressive residual stresses $(-500 \mathrm{MPa})$ relative to the $\mathrm{HAZ}$ that experiences high tensile residual stresses $(600 \mathrm{MPa})$. During PWHT, stress relaxation mechanisms [39] reduce both the compressive and tensile residual stresses in the CA6NM EB weld. In particular, during heating in a furnace to the PWHT temperature, the residual stresses decrease because of the reduction in the yield strength with temperature [40]. Then during holding at the PWHT temperature, the residual stresses decrease further through a combination of creep strain-induced relaxation [41] and phase transformation (tempered martensite). After PWHT, gradual cooling of the weld should limit increases in residual stress-that would occur due to the temperature dependency of the mechanical properties-and give a stress state with lower and more uniform compressive and tensile stresses compared to their initial levels.

Considering the minimum YS of $550 \mathrm{MPa}$ specified in ASTM A743-19 for CA6NM [12], these residual stresses in the EB weld after PWHT are quite low-less than $18 \%$ of the minimum YS value. The present findings corroborate well with the maximum residual stresses of $136 \mathrm{MPa}$ and $-152 \mathrm{MPa}$ reported, respectively, for the longitudinal and normal directions in multipass arc welded ASTM A743M Grade CA6NM after PWHT [42]. In consideration of the damage tolerance design approaches for welded CA6NM in hydroelectric turbines [43-45], reduction in the residual 


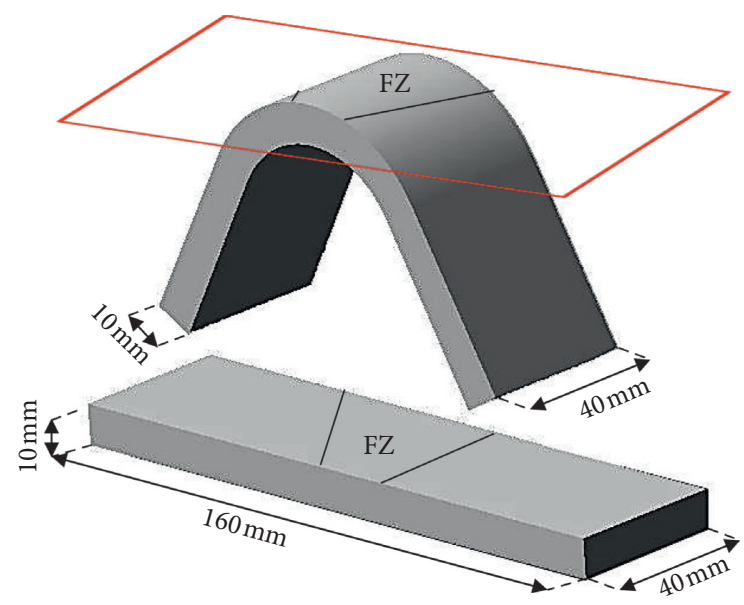

(a)

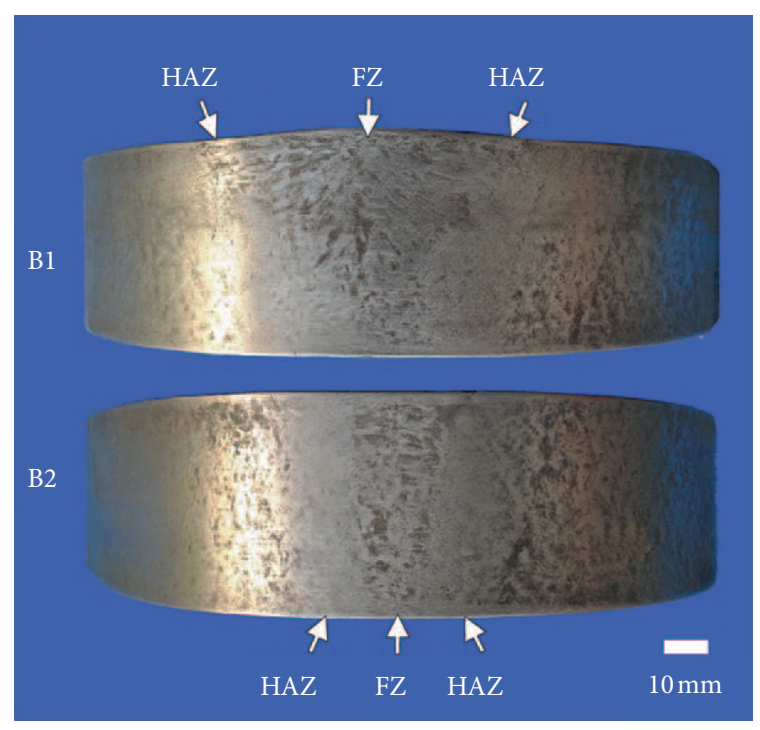

(b)

FIgure 12: Outer surface of the side bend tested samples of the EB butt weld.

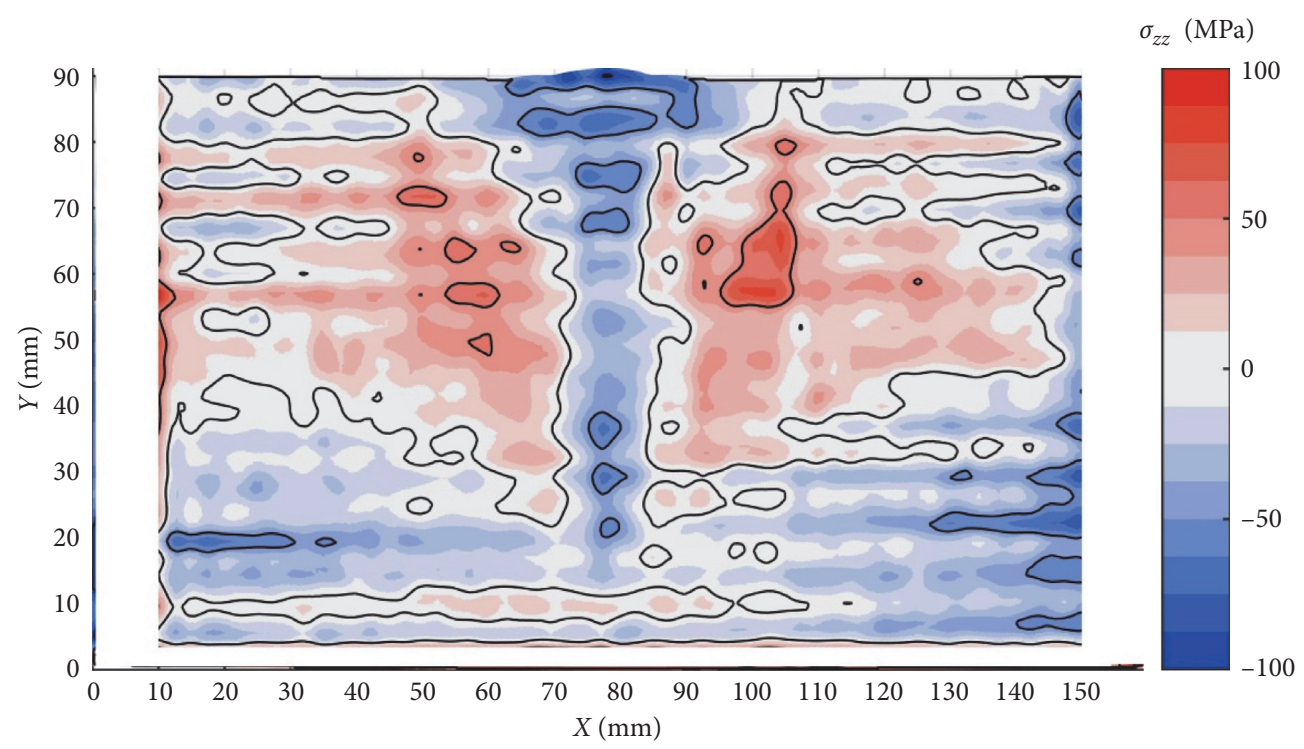

FIGURE 13: Longitudinal residual stress distributions in the CA6NM EB welds after PWHT.

stresses to levels between 10 and $25 \%$ of the YS [46] through PWHT have been reported to decrease the fatigue crack growth rate through plasticity-induced crack closure during dynamic loading [47]. Hence, the effective reduction in the tensile residual stresses in the HAZ after PWHT of the CA6NM EB welds is expected to improve the fatigue crack resistance, the extent of which needs to be validated through future work aimed at advancing a damage tolerant design, so as to understand the fatigue behaviour of high energy density welds in $13 \% \mathrm{Cr}-4 \% \mathrm{Ni}$ martensitic stainless steels.

From a perspective for hydroelectric turbine manufacturing, the qualitative and quantitative assessments undertaken in the present work highlight the good intrinsic mechanical resistance (high tensile strength and ductility, high toughness, good bend performance, and a low level of residual stresses) of the EB welds in CA6NM after PWHT, as well as the high potential for advanced assembly with a single pass process. Moreover, EB processing would benefit both manufacturing sustainability and environmental management through elimination of groove preparation, filler metal and gas shielding consumables, preheating, and multiple welding passes. Also, as the current PWHT practice in industry for arc welded CA6NM is directly applicable and appropriate for the EB welds, existing suppliers can be effectively relied on to provide services for the secondary operations after assembly. Finally, as an automated process, EBW would mitigate exposure of the workers to fumes and gases that would greatly contribute to improving the health and safety conditions in the workplace. 


\section{Conclusions}

The following conclusions can be drawn on the properties of EB welded joints in thick gage section CA6NM martensitic stainless steel after PWHT:

(i) The average global tensile properties adequately met the acceptance criteria based on the ASME Section IX standard (minimum UTS of $755 \mathrm{MPa}$ ). The fracture mechanism during tensile loading was observed from the fracture surfaces to consist of void nucleation at initiation sites such as inclusions or second phase particles, followed by growth and coalescence.

(ii) In the heavy section EB welds, the failure location during tensile loading depended on the constituents (FZ, HAZ, and BM) present in the GL of each sample. Failure occurred in the FZ (L1-L6 and T1) with FZ/GL $>0.50$ and in the HAZ (T2 sample) with $0.50 \leq \mathrm{FZ} / \mathrm{GL}<0.40$. By contrast, failure happened in the BM (T3-T4) with FZ/GL $<0.4$, when the GL consisted of all the constituents in the weld assembly: FZ, HAZ, and BM.

(iii) Using DIC, local properties ( $\mathrm{YS}_{\mathrm{L}}$ and strain) were determined for the different microstructural regions in the weldment (FZ, HAZ, and BM). Both the FZ and $\mathrm{HAZ}$ exhibited higher $\mathrm{YS}_{\mathrm{L}}$ relative to the BM. Also, the FZ exhibited a higher local strain (32\%) than the BM ( 28\%).

(iv) The average impact energies for the FZ and HAZ met the minimum requirements of $27 \mathrm{~J}$ specified in ASME Section VIII, Div. 1, and the more stringent requirement of $34 \mathrm{~J}$ at $-18^{\circ} \mathrm{C}$ of $\mathrm{GE}$ Renewable Energy. The impact energy in HAZ $(\sim 148 \mathrm{~J})$ was $\sim 2.2$ times more than the impact energy of the FZ $(\sim 63 \mathrm{~J})$, which was attributed to the different failure mechanisms in the HAZ (dimples) versus the FZ (quasi-cleavage consisting of facets and dimples).

(v) The EB welded joint was both high in quality and ductility without any discontinuities opening during side bend testing.

(vi) After PWHT, the longitudinal residual stresses in the EB welds were reduced to $\sim \pm 100 \mathrm{MPa}$ and distributed with a state of tension in the HAZ and compression in the FZ. The compressive state of the residual stresses in the $\mathrm{FZ}$ was attributed to the low temperature transformation of martensite.

\section{Abbreviations}

$\begin{array}{ll}\text { BM: } & \text { Base metal } \\ \text { CCD: } & \text { Charge-coupled device } \\ \text { CVN: } & \text { Charpy V-notch } \\ \text { DIC: } & \text { Digital image correlation } \\ \text { EB: } & \text { Electron beam } \\ \text { EBW: } & \text { Electron beam welding } \\ \text { EBZHT: } & \text { Electron beam zonal heat treatment } \\ \text { EDM: } & \text { Electrodischarge machining }\end{array}$

$\begin{array}{ll}\text { \%El: } & \text { Total percent elongation } \\ \text { FCAW: } & \text { Flux-cored arc welding } \\ \text { FZ: } & \text { Fusion zone } \\ \text { GL: } & \text { Gage length } \\ \text { GMAW: } & \text { Gas metal arc welding } \\ \text { HAZ: } & \text { Heat-affected zone } \\ \text { HLAW: } & \text { Hybrid laser arc welding } \\ \text { OM: } & \text { Optical microscopy } \\ \text { PWHT: } & \text { Postweld heat treatment } \\ \text { PWHTed: } & \text { Postweld heat treated } \\ \text { P- } \delta: & \text { Primary delta ferrite } \\ \text { SEM: } & \text { Scanning electron microscopy } \\ \text { S- } \delta: & \text { Secondary delta ferrite } \\ \text { UTS: } & \text { Ultimate tensile strength } \\ \text { XRD: } & \text { X-ray diffraction } \\ \text { YS: } & \text { Yield strength } \\ \text { YS }: & \text { Local yield strength } \\ \delta: & \text { Delta ferrite. }\end{array}$

\section{Data Availability}

The data used to support the findings of this study are included within the article.

\section{Conflicts of Interest}

The authors declare that there are no conflicts of interest regarding the publication of this paper.

\section{Acknowledgments}

The authors are grateful to GE Renewable Energy-Hydro North America (formerly Alstom), Hydro Quebec, the Natural Sciences and Engineering Research Council of Canada (NSERC), and the National Research Council of Canada (NRC) for financially supporting the Consortium de recherche en fabrication et réparation des roues d'eau (CReFaRRE). The authors also thank X. Pelletier, X. Lin, and M. Guerin of NRC for their technical assistance related to welding and mechanical testing with DIC. The authors are grateful to M. Sabourin of GE Renewable Energy-Hydro North America, and D. Thibault from IREQ for their useful advice and suggestions.

\section{References}

[1] A. H. Meleka, Electron Beam Welding: Principles and Practice, McGraw-Hill, London, UK, 1971.

[2] H. Schultz, Electron Beam Welding, Woodhead Publishing, Cambridge, UK, 1993.

[3] R. A. Saeed, A. N. Galybin, and V. Popov, "Modelling of flowinduced stresses in a Francis turbine runner," Advances in Engineering Software, vol. 41, no. 12, pp. 1245-1255, 2010.

[4] S. Kou, Welding Metallurgy, John Wiley \& Sons, Hoboken, NJ, UK, 2nd edition, 2003.

[5] M. Yada, T. Funamoto, M. Kitamura, J. Komatsu, M. Midorikawa, and T. Yoshikawa, "Water turbine runner and process for manufacturing the same," Patent US5035579, Hitachi, Ltd, Tokyo, Japan, 1991. 
[6] M. Blair and T. L. Stevens, Steel Castings Handbook, ASM International, Cleveland, OH, USA, 6th edition, 1995.

[7] S. Sarafan, P. Wanjara, H. Champliaud, and D. Thibault, "Characteristics of an autogenous single pass electron beam weld in thick gage CA6NM steel," The International Journal of Advanced Manufacturing Technology, vol. 78, no. 9-12, pp. 1523-1535, 2015.

[8] S. Sarafan, P. Wanjara, J. Gholipour, and H. Champliaud, "Global and local characteristics of an autogenous single pass electron beam weld in thick gage UNS S41500 steel," Materials Science and Engineering: A, vol. 666, pp. 360-371, 2016.

[9] S. Sarafan, P. Wanjara, J. Gholipour, H. Champliaud, and L. Mathieu, "Mechanical properties of electron beam welds in heavy-section UNS S41500 martensitic stainless steel," The International Journal of Advanced Manufacturing Technology, vol. 91, no. 9-12, pp. 4141-4150, 2017.

[10] S. Sarafan, P. Wanjara, J. Gholipour, H. Champliaud, L. Mathieu, and L. Mathieu, "Mehanical properties of electron beam welded joints in thick gage CA6NM stainless steel," Journal of Materials Engineering and Performance, vol. 26, no. 10, pp. 4768-4780, 2017.

[11] S. Sarafan, J.-B. Lévesque, P. Wanjara, J. Gholipour, and H. Champliaud, "Distortion and residual stresses in electron beam-welded hydroelectric turbine materials," Science and Technology of Welding and Joining, vol. 21, no. 6, pp. 473-478, 2016.

[12] ASTM A743-19, Standard Specification for Castings, IronChromium, Iron-Chromium-Nickel, Corrosion Resistant, for General Application, American Society for Testing Materials, West Conshohocken, PA, USA, 2019.

[13] M. Côté, Étude des Cinétiques de Transformation de Phase d'un Acier Inoxydable Martensitique $13 \% \mathrm{Cr}-4 \% \mathrm{Ni}$, École de Technologie Supérieure, Montréal, Canada, 2007.

[14] E. A. Schoefer, Steel Castings Handbook Supplement 7: Welding of High Alloy Castings, Steel Founders Society of America, Crystal Lake, IL, USA, 2004.

[15] S. Sarafan, P. Wanjara, H. Champliaud, L. Mathieu, and J. Lanteigne, "Characteristics of electron beam welded CA6NM," in Proceedings of the Material Science and Technology, Montreal, Canada, October 2013.

[16] F. R. Chen, L. X. Huo, Y. F. Zhang, L. Zhang, F. J. Liu, and G. Chen, "Effects of electron beam local post-weld heattreatment on the microstructure and properties of 30CrMnSiNi2A steel welded joints," Journal of Materials Processing Technology, vol. 129, no. 1-3, pp. 412-417, 2002.

[17] ISO 13919-1, Welding Electron and Laser-Beam Welded Joints, Electrons and Laser Beam Welded Joints. Guidance on Quality Levels for Imperfections, ISO, Geneva, Switzerland, 2019.

[18] ASTM-A480/A480M, Standard Specification for Castings Suitable for Pressure Service, Corrosion Resistant for General Application, American Society for Testing Materials, West Conshohocken, PA, USA, 2012.

[19] F. Hosseinzadeh, P. Ledgard, and P. J. Bouchard, "Controlling the cut in contour residual stress measurements of electron beam welded Ti-6Al-4V alloy plates," Experimental Mechanics, vol. 53, no. 5, pp. 829-839, 2013.

[20] M. B. Prime, "Cross-sectional mapping of residual stresses by measuring the surface contour after a cut," Journal of Engineering Materials and Technology, vol. 123, no. 2, pp. 162-168, 2001.

[21] S. Sarafan, P. Wanjara, J.-B. Lévesque, J. Gholipour, H. Champliaud, and L. Mathieu, "Residual stresses, microstructure and mechanical properties of EB welded 90-mmthick UNS S41500 martensitic stainless steel after PWHT," Materials Performance and Characterization, vol. 8, no. 4, pp. 648-663, 2019.
[22] ASTM-E384-11E1, Standard Test Method for Knoop and Vickers Hardness of Materials, American Society for Testing Materials, West Conshohocken, PA, USA, 2011.

[23] ASME, Boiler and Pressure Vessel Code Section IX, Qualification Standard for Welding and Brazing Procedures, Welders, Brazers, and Welding and Brazing Operators, American Society of Mechanical Engineers, New York, NY, USA, 2010.

[24] ASTM-E8/E8M-16a, ASTM Designation E 8-00 Standard Test Methods for Tension Testing of Metallic Materials, American Society for Testing Materials, West Conshohocken, PA, USA, 2013.

[25] ASTM-E8/E8M-16a, ARAMIS User Handbook, Gesellschaft fur Optische Messtechnik GmbH, Braunschweig, Germany, 2001.

[26] P. Wanjara, E. Dalgaard, J. Gholipour, X. Cao, J. Cuddy, and J. J. Jonas, "Effect of pre- and post-weld heat treatments on linear friction welded Ti-5553," Metallurgical and Materials Transactions A, vol. 45, no. 11, pp. 5138-5157, 2014.

[27] ASTM E23-12c, Standard Test Methods for Notched Bar Impact Testing of Metallic Materials, American Society for Testing Materials, West Conshohocken, PA, USA, 2012.

[28] ASME Boiler and Pressure Vessel Code, Section VIII, Division 1, Rules for Construction of Pressure Vessels, American Society of Mechanical Engineers (ASME), New York, NY, USA, 2007.

[29] P. D. Bilmes, M. Solari, and C. L. Llorente, "Characteristics and effects of austenite resulting from tempering of $13 \mathrm{Cr}$ NiMo martensitic steel weld metals," Materials Characterization, vol. 46, no. 4, pp. 285-296, 2001.

[30] B. K. Srivastava, S. Tewari, and J. Prakash, "A review on effect of preheating and/or post weld heat treatment (PWHT) on mechanical behaviour of ferrous metals," International Journal of Engineering Science and Technology, vol. 2, no. 4, pp. 625-631, 2010.

[31] F. Mirakhorli, X. Cao, X.-T. Pham, P. Wanjara, and J.-L. Fihey, "Post-weld tempered microstructure and mechanical properties of hybrid laser-arc welded cast martensitic stainless steel CA6NM," Metallurgical and Materials Transactions B, vol. 47, no. 6, pp. 3245-3256, 2016.

[32] T. L. Anderson, Fracture Mechanics: Fundamentals and Applications, CRC Press, Boca Raton, FL, USA, 2005.

[33] F. Foroozmehr, Ductile Fracture of 13\% Cr-4\% Ni Martensitic Stainless Steels Used in Hydraulic Turbine Welded Runners, M.E. thesis, Ecole Polytechnique, Palaiseau, France, 2017.

[34] M. Nystrom, P. Liu, T. Larsson, S. Olsson, and G. Svensk, "Impact fatigue of compressor valve steel," in Proceedings of the International Compressor Engineering Conference, pp. 511-516, West Lafayette, IN, USA, July 1996.

[35] Y. Iwabuchi, "Factors affecting on mechanical properties of soft martensitic stainless steel castings," JSME International Journal Series A, vol. 46, no. 3, pp. 441-446, 2003.

[36] F. Mirakhorli, X. Cao, X. T. Pham, P. Wanjara, and J. L. Fihey, "Hybrid laser-arc welding of 10 -mm thick cast martensitic stainless steel CA6NM: as-welded microstructure and mechanical properties," Metallurgical and Materials Transaction A, vol. 47, no. 7, pp. 3545-3563, 2016.

[37] L. Mathieu, GE Renewable Energy Company, Sorel-Tracy, Canada, 2014, Personal communication.

[38] J. Eckerlid, T. Nilsson, and L. Karlsson, "Fatigue properties of longitudinal attachments welded using low transformation temperature filler," Science and Technology of Welding and Joining, vol. 8, no. 5, pp. 353-359, 2003.

[39] Z. Feng, Processes and Mechanisms of Welding Residual Stress and Distortion, Woodhead Publishing Limited, Cambridge, UK, 2005. 
[40] J. E. Agapakis and K. Masubuchi, "Analytical modeling of thermal stress relieving in stainless and high strength steel weldments," Welding Research Supplement, vol. 6, pp. 187s196s, 1984.

[41] P. Dong, S. Song, and J. Zhang, "Analysis of residual stress relief mechanisms in post-weld heat treatment," International Journal of Pressure Vessels and Piping, vol. 122, pp. 6-14, 2014.

[42] D. Thibault, P. Bocher, M. Thomas, M. Gharghouri, and M. Côté, "Residual stress characterization in low transformation temperature $13 \% \mathrm{Cr}-4 \% \mathrm{Ni}$ stainless steel weld by neutron diffraction and the contour method," Materials Science and Engineering: A, vol. 527, no. 23, pp. 6205-6210, 2010.

[43] D. Thibault, M. Gagnon, and S. Godin, "Bridging the gap between metallurgy and fatigue reliability of hydraulic turbine runners," IOP Conference Series: Earth and Environmental Science, vol. 22, no. 1, Article ID 012019, 2014.

[44] M. Sabourin, D. Thibault, D.-A. Bouffard, and M. Levesque, "Hydraulic runner design method for lifetime," International Journal of Fluid Machinery and Systems, vol. 3, no. 4, pp. 301-308, 2010.

[45] A. Trudel, M. Lévesque, and M. Brochu, "Microstructural effects on the fatigue crack growth resistance of a stainless steel CA6NM weld," Engineering Fracture Mechanics, vol. 115, pp. 60-72, 2014.

[46] M. Sabourin, D. Thibault, and L. M. Bouffard, "New parameters influencing hydraulic runner lifetime," IOP Conference Series: Earth and Environmental Science, vol. 12, Article ID 012050, 2010.

[47] A. Trudel, M. Brochu, and M. Lévesque, "Residual stress effects on the propagation of fatigue cracks in the weld of a CA6NM stainless steel," in Proceedings of the 13th International Conference on Fracture, pp. 1-10, Beijing, China, June 2013. 